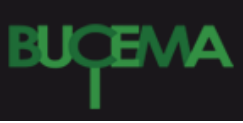

Bulletin du centre d'études médiévales d'Auxerre | BUCEMA

Hors-série $n^{\circ} 7 \mid 2013$

Les nouveaux horizons de l'ecclésiologie : du discours clérical à la science du social

\title{
Avant-propos : l'Église et la société, l'ecclésiologie et les sciences du social
}

\section{(2) OpenEdition}

\section{Journals}

Édition électronique

URL : https://journals.openedition.org/cem/12856

DOI : $10.4000 /$ cem. 12856

ISSN : 1954-3093

Éditeur

Centre d'études médiévales Saint-Germain d'Auxerre

Référence électronique

"Avant-propos : l'Église et la société, l'ecclésiologie et les sciences du social », Bulletin du centre d'études médiévales d'Auxerre | BUCEMA [En ligne], Hors-série n 7 | 2013, mis en ligne le 29 mars 2013, consulté le 02 mars 2023. URL : http://journals.openedition.org/cem/12856 ; DOI : https://doi.org/ 10.4000/cem. 12856

Ce document a été généré automatiquement le 2 mars 2023.

\section{(c) (i) (2)(2)}

Creative Commons - Attribution - Pas d'Utilisation Commerciale - Partage dans les Mêmes Conditions 4.0 International - CC BY-NC-SA 4.0

https://creativecommons.org/licenses/by-nc-sa/4.0/ 


\section{Avant-propos : l'Église et la société, l'ecclésiologie et les sciences du social}

1 La présente collection d'essais aimerait convaincre les lecteurs de la "nouveauté » d'une belle oubliée des sciences sociales: l'« ecclésiologie». Nouveauté pas tant du discours de l'Église sur elle-même, puisqu'il s'agit d'un phénomène historique qui remonte aussi haut que les premières " histoires ecclésiastiques ", telle celle d'Eusèbe de Césarée (265-339), que de l'introduction du phénomène ecclésial, de l'institution qualifiée d'Église comme mode d'organisation de la société, dans le périmètre d'investigation des chercheurs en sciences sociales: historiens, philosophes, sociologues, anthropologues, qui n'ont aucune raison d'en abandonner le traitement aux théologiens.

2 Fille de la Réforme, la réflexion savante sur l'Église devient en Allemagne, au cours du $\mathrm{XIX}^{\mathrm{e}}$ siècle, une branche de la théologie systématique tout en entretenant des liens génétiques avec les sciences historiques, et en subissant, dès les années 1880-1900, les effets collatéraux de la création d'espaces disciplinaires proches avec l'émergence de l'histoire et de la sociologie des religions. Mais il faut attendre les années 1930 et surtout l'Après-guerre pour que l'ecclésiologie soit examinée pour elle-même dans nombre d'écrits de synthèse en Allemagne ou en Italie, relayés en France par l'œuvre engagée d'Yves Congar. Discipline savante, l'ecclésiologie sert dès lors, pour le meilleur et le moins bon, les besoins divers et contradictoires suscités par l'aggiornamento de l'Église catholique. Cette histoire a fait l'objet de multiples travaux de la part d'historiens du christianisme contemporain et, plus encore, de sociologues des religions soucieux d'éclairer les fondements de leur discipline. Pour autant, il y a encore une ample matière à traiter par l'historien de la Chrétienté constantinienne, grégorienne et tridentine, sans doute plus à même que les spécialistes d'autres périodes à repérer les formes d'instrumentalisation de l'Église d'Ancien Régime aux origines de la tradition sociologique. Qu'on songe, par exemple, aux destins de la catégorie «Église " pour penser l'universel dans la philosophie du xVIII et du premier xIx ${ }^{e}$ siècle ; à la coloration fortement scolastique du vocabulaire de Gierke, familier des deux 
formes du Tout (omnes ut uniuersi, omnes ut singuli) ; à la distinction uniuersitas/societas dont use Durkheim dans sa lecture critique du contrat social de Rousseau, et à la définition scolastique d'universel qui lui permet de penser la société comme une totalité sui generis; ou encore aux usages de la «christomorphie» et de « angelomorphie » dans la conception que se fait Kantorowicz de la transcendance de la «personne mystique » du roi.

3 La présente publication en ligne n'a, bien sûr, pas la prétention de proposer une histoire exhaustive des formes du discours ecclésial aux origines des différents champs constitutifs des sciences sociales, mais elle voudrait ouvrir le chantier en ce sens, cela de deux façons. Les premières contributions de la collection cherchent à contraster l'œuvre d'un «fondateur ", engagé dans la réforme de l'Église de son temps (Y. Congar), avec celles d'un historien universitaire de la première institution ecclésiale (Alexandre Faivre) et de deux " passeurs » ne relevant en rien de l'ecclésiologie mais qui ont été l'un et l'autre amenés à se frotter à la question de la "gouvernementalité » et de la " théocratie » (Michel Foucault et Pierre Legendre). Sur la base de ces études de cas, qui pourraient (qui devraient) être multipliées, il s'agit de dessiner en creux le paysage dans lequel s'inscrit l'étude de l'Église aux époques de gestation et de renouvellement des sciences de la société (1900-1980). Ensuite, et au gré de diverses thématiques propres à qualifier l'institution ecclésiale (hérésie et dissidence versus orthodoxie du magistère ; matérialité et visibilité de la monumentale Église ; ritualité et fondements juridiques de l'institution), les textes rassemblés dans cette collection d'essais s'emploient à montrer comment les anciennes catégories " ecclésiales » ont offert aux pères de l'histoire et de la sociologie nombre d'outils de réflexion sur le social, cela au moment où l'ecclésiologie, sous des atours théologiques ou sous le couvert d'une histoire des dogmes, et, plus globalement, des diverses façons de faire l'histoire de l'Église, commençait à se constituer en discipline autonome. On cherche ici, en somme, par toute une série d'approches complémentaires, à montrer comment l'étude de l'ecclésial se confond longtemps avec celle du social, afin de mesurer les effets à long terme de l'ecclésiologie comme matrice de réflexions sur les mystérieuses alchimies qui constituent les communautés humaines. 